\title{
APLIKASI SISTEM PENDUKUNG KEPUTUSAN ANALISA KELAYAKAN PERPANJANGAN KONTRAK
}

\author{
Siti Aisyah*, Andika Cahyadi, Benny Wijaya, Mardi Turnip \\ Program Studi Sistem Informasi Fakultas Teknologi dan Ilmu Komputer, Universitas Prima Indonesia \\ E-mail: *siti_aisyah@unprimdn.ac.id
}

\begin{abstract}
ABSTRAK- Karyawan merupakan sumber daya yang paling berharga didalam sebuah organisasi. Kemajuan dari perusahaan salah satunya didukung dari kualitas karyawan yang baik. BCA salah satu instansi yang bergerak dibidang jasa perbankan. Tidak semua karyawan yang bekerja sudah menjadi karyawan tetap, ada beberapa diantaranya masih tercatat sebagai karyawan kontrak. Masalah yang sering dihadapi selama ini adalah sulitnya memilih karyawan yang akan dilakukan perpanjangan kontrak karena konsep penilaian masih bersifat konvensional. Sistem pendukung keputusan (SPK) merupakan salah satu aplikasi yang dapat membantu dalam proses pengambilan keputusan. SPK telah banyak digunakan sebagai alat bantu pemecahan masalah dalam sebuah keputusan didalam sebuah organisasi. Dengan melihat permasalahan yang dihadapi oleh Bank BCA dalam melakukan penilaian terhadap perpanjangan kontrak, maka perlu dibuat sebuah aplikasi yang dapat membantu dalam proses pengambilan keputusan agar sistem penilaian karyawan untuk perpanjangan kontrak menjadi lebih optimal. Dengan menerapkan metode topsis sebagai metode yang multikriteria, didapatkan penilaian terhadap data yang diuji adalah Christina Yaputra dengan nilai 0.7875, Andre Gumora dengan nilai 0.7694, Fendy Saputra dengan nilai 0.5018, Carvany dengan nilai 0.1462. Dengan kata lain, Christina Yaputra dan Andre Gumora akan mendapat perpanjangan kontrak karyawan diantara beberapa karyawan lain.

Kata kunci: Kontrak, Karyawan, Keputusan.
\end{abstract}

\section{PENDAHULUAN}

Karyawan merupakan sumber daya yang paling berharga didalam sebuah organisasi, performa dari karyawan harus terus ditingkatkan agar kegiatan perusahaan terus berjalan dengan lancar. Kemajuan dari perusahaan salah satunya didukung dari kualitas karyawan yang baik. BCA salah satu instansi yang bergerak dibidang jasa perbankan. Tidak semua karyawan yang bekerja sudah menjadi karyawan tetap, ada beberapa diantaranya masih tercatat sebagai karyawan kontrak. Masalah yang sering dihadapi selama ini adalah sulitnya memilih karyawan yang akan dilakukan perpanjangan kontrak.

Sistem pendukung keputusan (SPK) merupakan salah satu aplikasi yang dapat membantu dalam proses pengambilan keputusan. Beberapa penelitian yang pernah dilakukan seperti keputusan dalam hal pemberian beasiswa [1], kredit [2]. SPK dapat diterapkan dengan berbagai metode SAW [3], AHP, WP, dan lain sebagainya.

Dengan melihat permasalahan yang dihadapi oleh Bank BCA dalam melakukan penilaian terhadap perpanjangan kontrak karyawan, maka dibuatlah sebuah aplikasi yang dapat membantu dalam proses pengambilan keputusan. Dengan menerapkan metode topsis sebagai metode yang multikriteria diharapkan aplikasi ini dapat memberikan hasil keputusan yang maksimal.

\section{ISI PENELITIAN}

Sistem pendukung keputusan (SPK) merupakan suatu sistem interaktif yang membantu pengambilan keputusan melalui penggunaan data dan model- model keputusan untuk memecahkan masalahmasalah yang sifatnya semi terstruktur dan tidak terstruktur dimana tidak seorangpun tahu secara pasti bagaimana keputusan seharusnya dibuat.

\subsection{Karakteristik SPK}

Dari pengertian SPK, maka dapat ditentukan karakteristiknya antara lain:

- Mendukung seluruh kegiatan organisasi.

- Mendukung beberapa keputusan yang saling berinteraksi.

- Dapat digunakan berulang kali dan bersifat konstan.

- Terdapat dua komponen utama, yaitu data dan model.

- Menggunakan baik data eksternal dan internal.

- Menggunakan beberapa model kuantitatif.

\subsection{TOPSIS}

Technique for Order Preference by Similarity to Ideal Solution (TOPSIS) adalah salah satu metode pengambilan keputusan multikriteria menggunakan prinsip bahwa alternatif yang terpilih harus mempunyai jarak terdekat dari solusi ideal positif dan terjauh dari solusi ideal negatif dari sudut pandang geometris dengan menggunakan jarak Euclidean untuk menentukan kedekatan relatif dari suatu alternatif dengan solusi optimal [4]. Adapun langkah-langkah algoritma dari metode TOPSIS adalah sebagai berikut:

1. Menentukan normalisasi matriks keputusan. Nilai

$$
r_{i j}=\frac{x_{i j}}{\sqrt{\sum_{i=1}^{m} x_{i j}}}
$$


2. Menentukan bobot ternormalisasi matriks keputusan

$$
\begin{aligned}
y_{i j}=w_{i j} r_{i j} \\
A^{+}=\left(y_{1}^{+}, y_{2}^{+}, \ldots, y_{n}^{+}\right) \\
A^{-}=\left(y_{1}^{-}, y_{2}^{-}, \ldots, y_{n}^{-}\right)
\end{aligned}
$$

3. Menghitung Jarak antara alternatif $A_{i}$ dengan solusi ideal positif

$$
D_{i}^{+}=\sqrt{\sum_{j=1}^{n}\left(y_{j}^{+}-y_{i j}\right)^{2}}
$$

4. Jarak antara alternatif $A_{i}$ dengan solusi ideal negatif

$$
D_{i}^{-}=\sqrt{\sum_{j=1}^{n}\left(y_{i j}-y_{j}^{-}\right)^{2}}
$$

5. Menghitung Nilai preferensi untuk setiap alternatif $\left(\mathrm{V}_{\mathrm{i}}\right)$

$$
V_{i}=\frac{D_{i}^{-}}{D_{i}^{-}+D_{i}^{+}}
$$

\subsection{Microsoft Visual Basic}

Visual Basic (sering disingkat sebagai $V B$ ) merupakan sebuah bahasa pemrograman digunakan untuk ]program perangkat lunak berbasis sistem operasi Microsoft Windows yang menawarkan pengembangan perangkat lunak komputer berbasis grafik dengan cepat[5].

\section{HASIL DAN PEMBAHASAN}

Pada penelitian ini, metode TOPSIS digunakan untuk melakukan penilaian terhadap karyawan berdasarkan peringkat, dari nilai tertinggi atau yang paling layak untuk diberikan perpanjangan kontrak, ke nilai terendah. Aspek atau kriteria yang dinilai adalah:

- Tangible (Penampilan)

- Reliability (Keandalan)

- Responsiveness (Daya Tanggap)

- Assurance (Keyakinan dan Ketenangan)

- Empathy (Empati)

- Absensi (Ketidakhadiran)

Sebagai contoh perhitungan, diberikan 4 contoh data karyawan untuk diproses dengan menggunakan metode TOPSIS. Tabel 1 menampilkan contoh data dari empat karyawan.

Tabel 1. Contoh Data

\begin{tabular}{|c|l|r|r|r|r|r|r|}
\hline \multirow{2}{*}{ Kode } & \multirow{2}{*}{$\begin{array}{c}\text { Nama } \\
\text { Karyawan }\end{array}$} & \multicolumn{6}{|c|}{ Skala Nilai Kriteria } \\
\cline { 3 - 8 } & & C1 & C2 & C3 & C4 & C5 & C6 \\
\hline 80631999 & $\begin{array}{l}\text { Fendy } \\
\text { Saputra }\end{array}$ & 4 & 1 & 4 & 3 & 5 & 5 \\
\hline
\end{tabular}

\begin{tabular}{|l|l|r|r|r|r|r|r|}
\cline { 2 - 7 } 80635984 & $\begin{array}{l}\text { Andre } \\
\text { Gumora }\end{array}$ & 5 & 4 & 5 & 4 & 4 & 4 \\
\hline 80637026 & Carvany & 4 & 2 & 3 & 2 & 2 & 1 \\
\hline 80638506 & $\begin{array}{l}\text { Christina } \\
\text { Yaputra }\end{array}$ & 4 & 5 & 4 & 3 & 5 & 5 \\
\hline
\end{tabular}

Tabel 2. Matriks Nilai Ternormalisasi

\begin{tabular}{c|c|r|r|r|r|r|}
\hline Kode & C1 & C2 & C3 & C4 & C5 & C6 \\
\hline 80631999 & 0.4682 & 0.1474 & 0.4924 & 0.4867 & 0.5976 & 0.6108 \\
\hline 80635984 & 0.5852 & 0.5898 & 0.6155 & 0.6489 & 0.4781 & 0.4887 \\
\hline 80637026 & 0.4682 & 0.2949 & 0.3693 & 0.3244 & 0.2390 & 0.1222 \\
\hline 80638506 & 0.4682 & 0.7372 & 0.4924 & 0.4867 & 0.5976 & 0.6108 \\
\hline
\end{tabular}

Selanjutnya tentukan nilai bobot kriteria. Nilai bobot ditentukan secara manual, sesuai dengan penting atau tidaknya suatu kriteria. Oleh karena semua kriteria dianggap sama penting, maka nilai bobot sama, seperti terlihat pada tabel 3. berikut.

Tabel 3. Nilai Bobot Kriteria

\begin{tabular}{|l|l|r|}
\hline Kode & \multicolumn{1}{|c|}{ Kriteria } & Bobot \\
\hline C1 & Tangible (Penampilan) & 1 \\
\hline C2 & Reliability (Keandalan) & 1 \\
\hline C3 & Responsiveness (Daya Tanggap) & 1 \\
\hline C4 & Assurance (Keyakinan dan Ketenangan) & 1 \\
\hline C5 & Empathy (Empati) & 1 \\
\hline C6 & Absensi & 1 \\
\hline
\end{tabular}

Setelah bobot ditentukan, maka berikutnya adalah dilakukan perkalian antara matriks ternormalisasi dengan nilai bobot. Contoh perhitungan pada baris 1 dan kolom $1=0.4682 \times 1=$ 0.4682 .

Tabel 4. Hasil Perkalian Matriks Ternormalisasi

\begin{tabular}{c|r|r|r|r|r|r}
\hline Kode & C1 & C2 & C3 & C4 & C5 & C6 \\
\hline 80631999 & 0.4682 & 0.1474 & 0.4924 & 0.4867 & 0.5976 & 0.6108 \\
\hline 80635984 & 0.5852 & 0.5898 & 0.6155 & 0.6489 & 0.4781 & 0.4887 \\
\hline 80637026 & 0.4682 & 0.2949 & 0.3693 & 0.3244 & 0.2390 & 0.1222 \\
\hline 80638506 & 0.4682 & 0.7372 & 0.4924 & 0.4867 & 0.5976 & 0.6108 \\
\hline
\end{tabular}

Setelah itu, ditentukan nilai maksimum dan nilai minimum dari masing-masing kolom, seperti dapat dilihat pada tabel 5 berikut.

Tabel 5. Nilai Maksimum dan Minimum Kriteria

\begin{tabular}{|l|r|r|r|r|r|r|}
\hline & C1 & C2 & C3 & C4 & C5 & C6 \\
\hline Maks (+) & 0.5852 & 0.7372 & 0.6155 & 0.6489 & 0.5976 & 0.6108 \\
\hline Min (-) & 0.4682 & 0.1474 & 0.3693 & 0.3244 & 0.2390 & 0.1222 \\
\hline
\end{tabular}

Hasil perhitungan solusi ideal positif dan solusi ideal negatif dapat dilihat pada tabel 6 berikut.

Tabel 6. Solusi Ideal Positif dan Negatif

\begin{tabular}{|c|c|c|}
\hline Kode & Solusi Ideal + & Solusi Ideal - \\
\hline 80631999 & 0.6348 & 0.6394 \\
\hline 80635984 & 0.2256 & 0.7529 \\
\hline 80637026 & 0.8617 & 0.1475 \\
\hline 80638506 & 0.2348 & 0.8699 \\
\hline
\end{tabular}


Setelah solusi ideal positif dan negatif diperoleh, maka langkah berikutnya adalah mencari nilai ideal

Tabel 7. Hasil Rangking TOPSIS dan Penentuan Perpanjangan Kontrak

\begin{tabular}{|c|c|r|c|}
\hline Kode & Nilai & Rangking & $\begin{array}{c}\text { Perpanjan } \\
\text { gan } \\
\text { Kontrak }\end{array}$ \\
\hline 80638506 & 0.7875 & 1 & Ya \\
\hline 80635984 & 0.7694 & 2 & Ya \\
\hline 80631999 & 0.5018 & 3 & Tidak \\
\hline 80637026 & 0.1462 & 4 & Tidak \\
\hline Dengan demikian, pengurutan rangking
\end{tabular}
dilakukan dari nilai preferensi tertinggi ke terendah, dengan hasil akhir dapat dilihat pada tabel 7 . Apabila ditentukan bahwa hanya 50\% karyawan dengan nilai tertinggi akan memperoleh perpanjangan kontrak.

\subsection{Tampilan Aplikasi}

\section{Menu Utama}

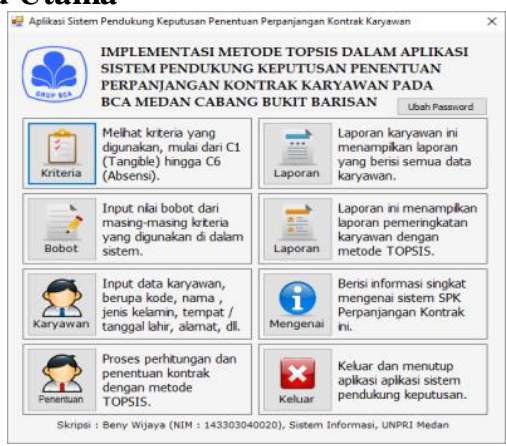

Gambar 1. Menu Utama

Pada form Utama, terdapat beberapa tombol untuk mengakses form yang terdapat di dalam aplikasi. Tombol "Kriteria" berfungsi untuk menampilkan form Kriteria. Tombol "Bobot" berfungsi untuk menampilkan form Bobot. Tombol "Karyawan" berfungsi untuk menampilkan form Karyawan. Tombol "Penentuan" berfungsi untuk menampilkan form Penentuan. Tombol "Laporan Karyawan" berfungsi untuk menampilkan laporan karyawan. Tombol "Laporan Hasil" berfungsi untuk menampilkan laporan hasil. Tombol "Mengenai" berfungsi untuk menampilkan form Mengenai, tombol "Ubah Password" untuk menampilkan form Ubah Password, dan tombol "Keluar" berfungsi untuk menutup form.

\section{Form Kriteria}

Form kriteria berfungsi untuk menambahkan atau mengedit kriteria yang diperlukan oleh pihak manajemen dalam proses perpanjang kontrak

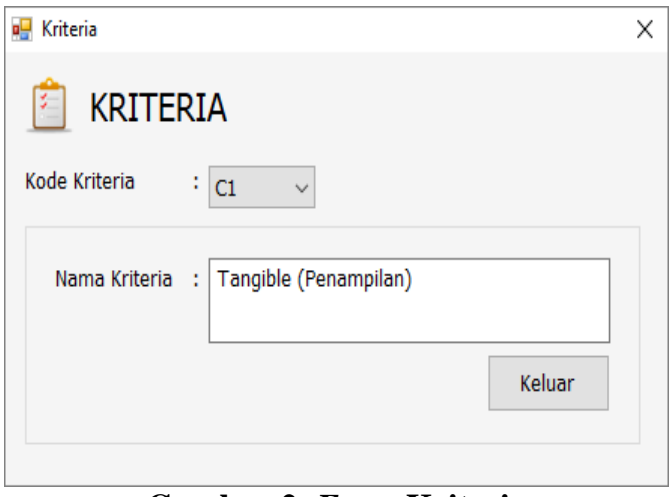

Gambar 2. Form Kriteria

\section{Form Bobot}

Form bobot berfungsi untuk memberikan nilai kepada masing-masing kriteria yang dipakai.

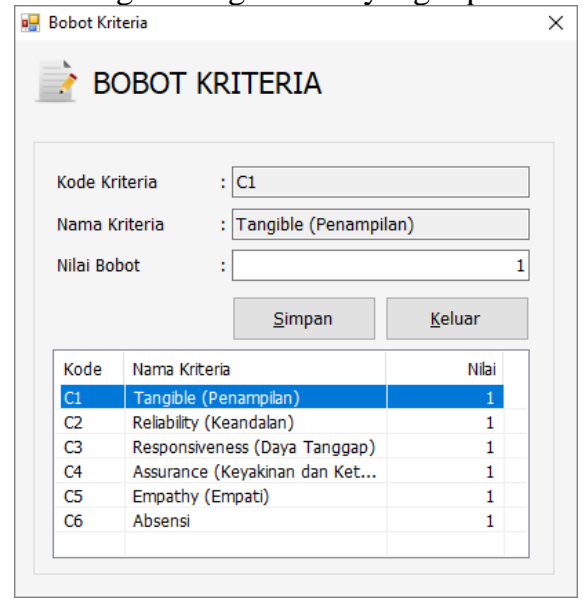

Gambar 3. Form Bobot

\section{Form Karyawan}

Form karyawan digunakan untuk menambhkan atau memasukkan data serta mengedit atau memperbaharui identitas karyawan.

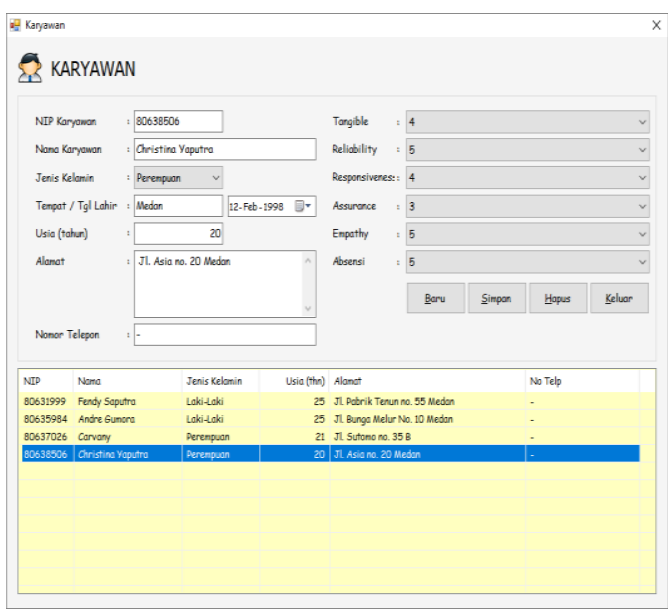

Gambar 4. Form Karyawan

\section{Form Perhitungan/Penentuan}

Form ini berfungsi untuk melakukan proses perhitungan dari masing-masing penilaian yang nantinya akan dijadikan sebagai pengambilan keputusan. 


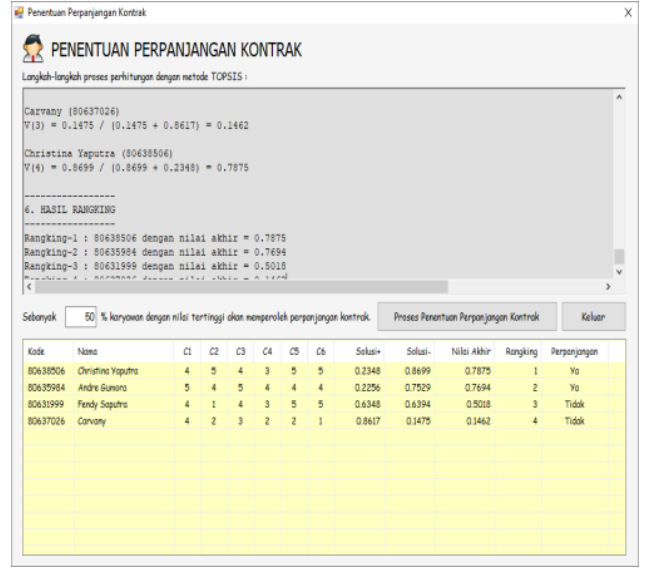

Gambar 5. Form Penentuan

\section{Laporan Data Karyawan}

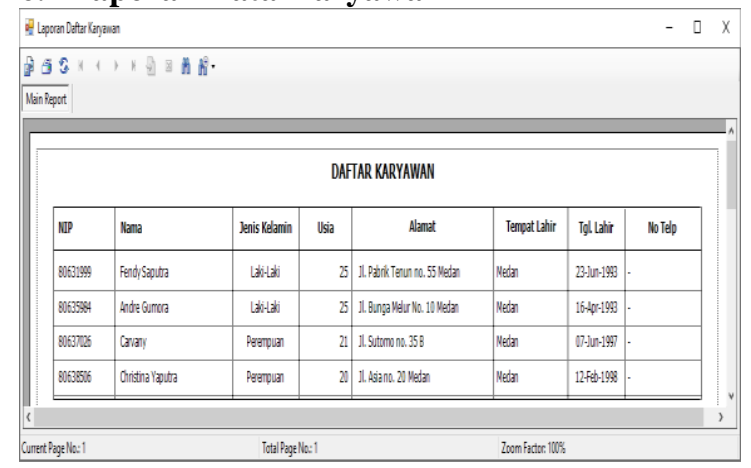

Gambar 6. Laporan Data Karyawan

\section{Laporan Hasil}

\begin{tabular}{|c|c|c|c|c|c|c|c|}
\hline \multicolumn{7}{|c|}{ 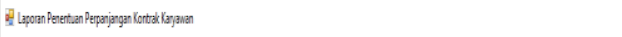 } & $-\square x$ \\
\hline \multicolumn{8}{|c|}{ 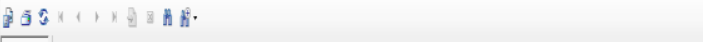 } \\
\hline \multicolumn{8}{|l|}{ Manlepont } \\
\hline \multicolumn{8}{|c|}{ LAPORANPENENTCANPERPANJAIGANKONTRAKKARYAWAN } \\
\hline Ranghing & kode & Nana & Jeris kalarin & Alenat & litelp & Wilia Ahkir & 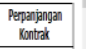 \\
\hline & 8033536 & Chistiallapula & Pyerpial & 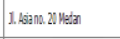 & & 0,065 & $y_{3}$ \\
\hline 2 & 8063584 & Ante auncua & Ldildaj & 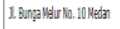 & & D.to4 & ra \\
\hline 3 & 8063:300 & Fad (Saptra & 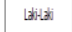 & 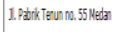 & & 0.5018 & Tida \\
\hline & 8033726 & (andi) & Pyerp:ala & 1.5tatmonn 3.58 & & 01462 & Tidj. \\
\hline & & & & & & & \\
\hline Curnet Prygllb: 1 & & & Totd ligeflib:1 & & Zlom fittox: & & \\
\hline
\end{tabular}

Gambar 7. Laporan Hasil

\section{PENUTUP}

Beberapa hal yang dapat disimpulkan dari penelitian ini adalah sebagai berikut:

1. Dengan menerapkan konsep multikriteria aplikasi ini cocok digunakan dalam proses pengambilan keputusan

2. Aplikasi sistem pendukung keputusan ini dapat digunakan untuk membantu penentuan perpanjangan kontrak karyawan pada BCA Medan cabang Bukit Barisan.

3. Diharapkan dapat dilakukan pengembangan dalam model platform yang lebih baik lagi.
4. Penggunaan metode lainnya dapat dijadikan sebagai tolak ukur atau perbandingan seperti metodi AHP,WP, maupun Elektre

\section{DAFTAR PUSTAKA}

[1] Gunawan., Ririn Prananingrum Kesuma., Dkk (2013).Pengembangan sistem penunjang keputusanpenentuan pemberian beasiswa tingkat sekolah.Jurnal Sarjana Sistem Informasi 2013.Volume 14 No.2 Hal 2.STMIK Mikroskil Medan.

[2] Oktaputra dan Noersasongko.2014.Sistem Pendukung Keputusan Kelayakan Pemberian Kredit Motor Pada Perusahaan Leasing HD Finance.Semarang: Dian Nuswantoro.

[3] Desriyanti, Munirah Muslim, (2015). "Sistem Pendukung Keputusan Pemberian Bantuan Masyarakat Miskin Menggunakan Metode Simpel Additive Weighting (SAW)". jurnal Teknik Elektro, Fakultas Teknik, Universitas Muhammadiyah Ponorogo. Ponorogo.

[4] Shalehah, A. 2014.Penerapan TOPSIS (Technique for Order Preference by Similarity to Ideal Solution) untuk Seleksi Penerimaan Beasiswa.Jakarta: Universitas Brawijaya.

[5] Wahana Komputer.2010.Panduan Aplikatif dan Solusi (PAS) Membuat Aplikasi Client Server dengan Visual Basic 2008.Yogyakarta:Andi. 